\title{
Deconstruction and Self-reflection - Polish Ethnographic Atlas in the Perspective of Selected Memory Theories: An Attempt at Theoretical Approach
}

\begin{abstract}
The purpose of this text is to critically discuss the method of collecting source materials as part of the Polish Ethnographic Atlas project and the ways to interpret them and to develop innovative interpretation strategies for these data, which until now are stored in the archives of this Atlas. These strategies will allow to use messages that have been rejected in ethnogeographical analyses and interpretations so far. These are primarily the records of spontaneous representations of narratives and the memory of the inhabitants of the village. What determined their significance and the role they played in learning about the reality examined was the fact that they constituted an individualized form of narrative. They were not triggered by a question in any way, so they were unique. These features made comparative studies impossible. Nevertheless, thanks to them, the interpretation of reality contained in the performances gained a context. Understanding the significance of these performances during the research was almost impossible, it took place at the level of the researcher's intuition. The change of the paradigm allowed to extract a new cognitive value from them and gave the possibility of their redefinition and re-evaluation.
\end{abstract}

Keywords: theory of memory, representations of memory, narratives

\section{Introduction}

Research and the understanding of culture are complex activities and subject to ongoing negotiations. This situation results from the fact that researchers are car- 
riers and co-creators of specific cultural systems. This in turn causes that every attempt to describe culture introduces the cultural perspective of the researcher as an individual being a member of a given community functioning in a given system and a perspective resulting from the system itself. Assumptions defining the method and purpose of the research undertaken by the creators of the Polish Ethnographic Atlas (PEA) were far-reaching. It was assumed to get to know about the diversity and dynamics of the so-called traditional culture in Poland within its borders established after the Second World War. This goal was achieved by collecting extremely detailed data collected during intensive field research in more than three hundred villages. The collected source materials were elaborated and read in the context of the ethnographic method and taking into account the research assumptions developed, among others, by Kazimierz Moszyński, Józef Gajek and Zygmunt Kłodnicki. These are the assumptions that had their beginning in the first half of the $20^{\text {th }}$ century, and thus functioning unchanged for over half a century. Researchers using this method, analysing and then interpreting narratives and field research, so far have not taken into account the changes occurring at the time in the field of perceiving images of the past. New concepts that emerged in the humanities and social sciences at the turn of the $20^{\text {th }}$ and $21^{\text {st }}$ centuries, allow not only for the inclusion of a new perspective in the perception of past events but also for a different, more innovative approach to archival materials. These concepts have not been translated and applied in analyses relating to archival materials of the Polish Ethnographic Atlas so far. This situation condemned such a huge collection of news about rural reality and its transformation into marginalization. However, narrowing the interpretation perspective only to ethnographic methodology (less frequently retrospective) made it impossible to undertake a scientific discourse on subjective representations of the past recorded in the memory of the interlocutors. Thus, the goal for which I focused on the aforementioned issues was an attempt to deconstruct the assumptions of the atlas research and an attempt to modernize strategies for the interpretation of source materials collected as part of the project of the Polish Ethnographic Atlas, which until now are stored in the archives of this Atlas.

\section{Deconstruction and self-reflection}

Precisely elaborated goals that were to be achieved through field research conducted on a large scale focused on two fundamental themes: the genesis of folk culture in Poland and its regional diversity that was taking place at a specific time. Properly formulated questions as well as information extracted from the answers obtained, information matching the assumed concept, allowed for the preparation of a series of ethnographic maps enabling appropriate interpretation and inference. The conclusions that were made on the basis of the aforementioned 
cartograms were included in subsequent studies, which were Comments on the Polish Ethnographic Atlas. Thus, the collected material was considered as a precise representation of the past. This was indicated by the argument that the material was collected by specialized staff and by identical questionnaires which, in the end, allowed to believe that these data were completely objective. In this approach, it was also possible to handle information collected in any way.

During my scientific and research work at the studio of the Polish Ethnographic Atlas, I conducted field research in several villages - PEA research centres in north-eastern and eastern Poland. The idea of these activities was to supplement the source material previously collected with messages from the locality that had not been studied so far. Research trips usually lasted for a week - up to ten days. At that time, it was usually necessary to study four villages. It required several (two or three) interviews on one subject, which resulted in about 8-12 extended interviews in one village. It is worth emphasising here that the interview questionnaires had a form of several to several dozen questions of varying degrees of complexity. As a rule, these were closed questions focused on many detailed issues. ${ }^{1}$ In a few cases, open questions appeared that gave - at least in theory - the possibility of free speech of the interlocutor. All these research tools prepared by PEA employees (mainly Gajek [e.g. 1956: 899-912, 1959: 153-204, 1976: 143-177], over time slightly modified by Kłodnicki [e.g. 2009: 45-59]) were subordinated to the developed thesis and did not take into account individual experiences gained during stay in the field. In the last studies conducted after 2000, the same scheme was also required.

In atlas studies, the main purpose of an ethnographer staying in the field was to 'collect' information. ${ }^{2}$ The conviction about the possibility of collecting data, confronted with reality, turned out to be illusory. The information the researcher needed could not be obtained without the person who had it. At present, this statement is obvious, while during field explorations it was only a kind of intuition accompanying the researcher. This unverbalised premonition, which marked subsequent stays in the field, can be characterized by the words of Clifford Geertz:

However, this leads to the perception of anthropological research as a form of activity rather observational than interpretative, which somewhat distorts its true image. Already on the most basic of the basic levels of our entire project-at the level of the irrefutable facts (if this level exists at all...) - we are subject to the process of explication: worse, we explicate something that is already someone's explication [...] (Geertz 2005: 24).

1 In the future, they are to enable the typology or classification of the studied cultural phenomena and then translate this information into the language of symbols placed on ethnographic maps.

2 Using the metaphor used by Bruner (2011b: 152) - information treated as ripe fruits that lie and wait to be reached for. 
and a little further:

This 'getting the feel', which flusters us and enterprise, which can never be fully successful, is the content of the ethnographic research at the level of personal experience; the attempts to formulate the grounds on which, always in an exaggerated manner, we want to base our belief that here we achieved this objective, they are what constitutes the content of anthropological writing as a scientific project (Geertz 2005: 28).

In the research situation the action consisting of gathering factual data meet the whole scale of moments and experiences resulting from the basic human behaviour, which is conversation. This dissonance, incompatibility and inaccuracy - however unspecified, they had to be reflected in the source materials.

During field research, the ethnographer was subjected to double pressure. On the one hand, it was the pressure of time and substantive requirements set by the editors of the Atlas, on the other hand, their own intuitions and doubts born in confrontation with the reality. ${ }^{3}$ The researcher went to other places as an expert equipped with knowledge and research tools, counting on gathering information - 'bare facts' that will verify and deepen the knowledge already possessed. The quantity and quality of the required messages had a significant impact on how the ethnographer moved in the field. However, on the spot, it was not the collection of the abstracted source material that complicated the research, but the situation of contact with a man who was the depositary of important messages for the researcher. The requirements set for the ethnographer by the creators of the Atlas did not take into account social factors, individualized behaviours and subjective assessments of people participating in the research situation. However, they, paradoxically, determined which empirical material could have been obtained. Thus, the paradigm of objective and representative supra-unit data (if they exist) depends on the individualized and non-standardized activities of researchers and their interlocutors. The necessity of obtaining many accurate, well-defined information in a relatively short period of time meant that the ethnographer was subject to orders that influenced its course from the very beginning of the trip to the area. Staying at the research site was associated with the need to establish contact, inspire confidence of strangers and acquire detailed knowledge on specific subjects in just a few days. The ability to establish interpersonal contact determined whether the ethnographer would be able to establish such close relationships with members of the community to be able to conduct long conversations. On the other hand, the ability to negotiate one's own position in a newly established relationship and to explain the need for conversation made it possible to gain the help of an introductory person who directed the researcher to members of the community who possessed knowledge on a given subject. It was one of many possible situations that occurred in the field. Another common practice was the search for random interlocutors - usually older people who wanted to devote their time to

\footnotetext{
3 I write more on this subject in: Drożdż 2018.
} 
talk. The creation of new, both for the researcher and the interlocutor, circumstances required participants to make an effort to establish a relationship.

Another, equally important field experience, was the confrontation not only with the individual, but above all with the local community. The ethnographer, who had only a few days to conduct interviews, was totally dependent on the way of being adopted by the group. The arrival of people from the outside of the village was communicated even before the person actually arrived. In this way, the researcher became the object of interest, the activities and the purpose of the visit were discussed by the locals. This moment of reversal of roles, although almost unnoticeable, was a turning point during the research. It made the researcher realize that "there are no virgin meetings and naive experiences, because people, including ethnographers, always enter society during its existence" (Bruner 2011a: 22 ), and this entrance always has specific consequences. This destroyed the idealistic assumption of the possibility of separating the description of the examined artifact (a phenomenon) from its author and recipient. It also significantly influenced the way in which observed and experienced situations were recorded and the narratives heard. The researcher - a participant in this new relationship and at the same time its registrar - struggled with the burden of talking about what others talk about, while realizing that in the Atlas studies, 'facts' have to speak, not people. The effort put into field records consisted in separating the message, information from the context of the situation and the ethnographer's own experience. The term 'experience' is actually a word - a key, although it was not taken into account during the research.

Both situations mentioned above took place during my research. At the same time, these were for me one of the most difficult exploratory experiences, despite quite intense stays in the field. In the following years, 2000 and 2001, I participated in several research trips, usually lasting several days. During this time, I visited 13 villages and talked to over a hundred people. Thanks to this, I experienced their presence, got to know opinions and often emotions as well.

While arriving in a completely unknown place where I had to spend some time, the situation of confrontation with the local community was inevitable. It was my individual experience - the researcher as an individual - that caused this 'local community' to take on very specific shapes in the form of people who host (staying in the field was often associated with the fact that I not only talked with the residents of the village, but also stayed with them at home, I was eating meals with them) but also conduct a conversation. This common experience of everyday life brought about a relationship between us: ambiguous, unreadable and with more question marks than answers. Its provoked questions about how to talk about 'facts, ${ }^{4}$ extracted from complex systems and ambiguous contexts of cultural phenomena. How to talk with people who, for a short moment, became

4 I put the word 'fact' in quotation marks since I am aware that the information obtained during the interviews consists of certain variants of facts: memory, generalization, interpretation. However, 
our partners in a dialogue and equal interpreters of culture. It allowed to understand Geertz's words better since "the boundary between $[. .$.$] culture as a certain$ natural fact and [...] culture as a certain theoretical being has a tendency to blur" (Geertz 2005: 30).

In a short time of staying in the studied place, each of us - ethnographers usually went to the elderly, who, according to the assumption, had the most complete knowledge, on subjects developed within the Ethnographic Atlas. During the interviews, there were fluctuations around phenomena that took place in the past or those that were considered to be disappearing. ${ }^{5}$ Elderly person became an expert with information that was not (as assumed) known to the representatives of the younger generation. The openness of these people meant that many hours of conversation were held with them, addressing a whole range of issues. Thanks to this, their image of the studied phenomena became the one that formed the basis for building a general image of the studied culture. The narratives of these people referred to the past in which events from their own lives were placed, as well as those that relate to episodes known from the stories of their parents and grandparents. The events taking place in the present times evoked further memories. It is impossible not to notice that the consequence of such action was the fragmentation and context of the images received. This drawback was also caused by the fact that its outline was drawn through the theoretical frames imposed by the researcher. The narratives concerned the past, which had a blurred beginning, defined by relative time, which indicated that they were part of a larger, extremely important whole. Its importance derived from the fact that it was treated as a research phenomenon. After it, the present took place, which included the life of the narrator. However, despite the fact that it was full of events, it lost its importance. It was such a manifestation, a form of culture for which ethnogeographers did not have analytical categories and interpretative tools. The stories about it became illegible and useless.

The stories of which we were recipients as the researchers were taking place on two levels. The first one concerned situations in which the interlocutors worked out their own generalizations. The idea was to draw up definitions with the help of which they could answer questions concerning common forms in the examined locality. Thus, these generalizations did not clearly reflect reality but constituted its interpretation. This action was of a secondary character, because it was caused by the interest of a stranger from the outside. This narrative was supposed to present the studied phenomena as a kind of an image of the questioned person, about

at the time of collecting source materials for the PEA project, these facts were of a nature of objective statements.

5 These activities resulted from precisely defined theoretical framework and assumed effects, which were to be achieved by conducting the so-called atlas research, I discuss this issue in details in: Drożdż 2018. 
what the researcher wanted to hear. This led to the development of a kind of synthesis for the needs of the interview.

The next level of narrative concerned individual events, occupying a significant place in the autobiography of a particular interlocutor. The phenomenon or artifact that was the subject of the research triggered memories. They were not directly provoked by the question but they were spontaneous. Their appearance was a bit of a problem, as they escaped the rigid framework of the questionnaire. Nevertheless, an attentive listener was aware of their importance. The researcher's intuition suggested that thanks to them it would be possible to 'place' the facts given by the interlocutor in a broader socio-cultural context. It would also facilitate the viewing of culture from the perspective of a man for whom it was a natural environment of everyday life. Such narratives appeared frequently and played a significant role in the interlocutor's statements. Subjective considerations often determined which topics the researcher would keep: an interesting plot, a reference to the main thread of the conversation, the situational context of the conversation and even the person of the narrator itself. A large number of such 'spontaneous statements' written down by dozens of field researchers involved in the project, such as the Polish Ethnographic Atlas, indicate that the described situations and dilemmas were their everyday life. The extraction of these records from several thousand of questionnaire cards allows us to look at the studied phenomena from a different perspective.

\section{Selected theories of memory and representation - Polish Ethnographic Atlas in new contexts}

At both levels of the statements referred to above, the researchers listened not to the exact imaging of the past but to its representation. It is a place to refer to the theory of survival and expression developed by Wilhelm Dilthey. Edward M. Bruner describes it in the following words:

Survival is culturally constructed, whereas understanding implies experiencing. In these dialogical relationships, Dilthley did not see an impossible to solve dilemma, but on the contrary, he considered them to be the basis of the nature of data in the humanities itself. [...]. There is a critical distinction between reality (something that really is, regardless of what it is), survival (how this reality is made present in the perception), and expression (how a single experience is formulated and expressed). In the totality of life [...] there is a distinction between life as something that is implemented (reality), life as something that is lived (experience), and life as something that is told (expression)(Bruner 2011a: 14).

These expressions revealed during the contact between the narrator and the listener took on differently structured forms. They depend on many factors, including: the context of the situation, who the sender and recipient were. In this way they became "socially constructed units of meaning" (Bruner 2011a: 15). The richness of these expressions is manifested in various, often 
multiplied forms of performances/representations. It is on the latter that memory is assumed on the re-presentation of the past, which takes place through language, narrative, image and sound. In this approach, re-presentations are perceived as ways of articulating the past (see Huyssen 2009, according to Saryusz-Wolska 2009: 27).

A Polish anthropologist Katarzyna Kaniowska distinguishes three basic ways of understanding this concept in the context of research of the past: as a substitute (of things, facts, events); as a real presence of what is absent and as an image of reality (Kaniowska 2013: 55). The researcher states that "in each of the above meanings, the performance becomes necessary to analyse some other problem appearing in cognition; Another difficulty that must be faced by a researcher who has the human world as the object of research, that is, the area of human experience" ( Kaniowska 2013: 55). ${ }^{6}$ This concept gives the possibility of gaining a new, original redefinition of the Atlas source materials. This concept gives the opportunity of a new understanding of the content of atlas source materials. In turn, reaching for previously overlooked resources contained in these records allows to change the cognitive perspective and introduce new interpretative possibilities.

In the first way of understanding the discussed term, the function of representation as the one that substitutes for something that is or was a fact is important. Thanks to this, everything that has been stored in human memory constitutes the whole of knowledge about the surrounding world. Continuous processes of remembering/perpetuating and forgetting/throwing away from memory the encoded events lead to constant interpretation and re-construction of the past. These activities accompany people throughout their whole lives and do not lose their dynamics. Their effect is represented by the past constructed from ordered sequences of representations of experienced events. They constitute a reservoir of knowledge about the world gained on the basis of experience. They are the basis of communication in interaction with another person, thanks to which it is possible to get to know ways of understanding the reality by the interlocutor. Kaniowska stresses that " $[\ldots]$ for the understanding of a given reality, both the participant and the researcher need the meanings given to things and representations of things. They only allow to recreate the processes of using and interpreting the world, and thus the way of understanding reality" (Kaniowska 2013: 57). In this way, the ethnographer, who initiates a conversation with the interlocutor, meets only the representations of reality - its substitutes:

It is worth emphasising again that the experience retained in memory is a substitute for past real experience and that the substitute came into existence as a result of the entity's passing through

${ }^{6}$ I am aware that the $20^{\text {th }}$ century, in particular the turn of the $20^{\text {th }}$ and $21^{\text {st }}$ centuries, is a period of a kind of a 'memory boom'. Explorations on this issue have been the subject of a number of important studies in many scientific disciplines. Memory research has thus become an extremely current transdisciplinary project requiring an interdisciplinary approach. It is impossible to bring all the current arrangements in this area at this point (see Drożdż 2018). For the purposes of these considerations, I refer only to selected concepts of the memory. 
what has passed and at the same time, it is also a trace that the facts of the past left in the consciousness of the subject. It means that the presentation 'flowing' from memory is an interpretation and at the same time an effect of interpretation (Kaniowska 2013: 58).

Taking into account the research situation, during which the 'local' contact takes place - between the depository of knowledge about the examined reality and a 'stranger' - an investigator who poses questions, another form of representation can be pointed out, the representation of memory. The result of the dialogue is the narration that satisfies above all the ethnographer. The information of the past is extracted from the informant's memory, however, the stories, the recipient of which is the researcher, are only a fragmentary image representing the memory. This means that narrations of informers do not contain all possible representations of the past, but only these that interest the listener and these that during the conversation were implied by the narrator's memory. These are images that have been consumed and refined, selected from a number of others that are generally known around the world. This observation allows us to assume that while in the building of the knowledge and self-knowledge of the respondent, the representation understood as a substitute participates in the transmission and registration of this knowledge, representations regarded as 'the real presence of what is absent' are taken into account. In this case, the researcher plays the decisive role, which becomes the depository of knowledge provided by the interlocutors during the interview. The ethnographers not only records but, above all, interpret the situation of which they are the co-creators and participants. As Kaniowska emphasises:

Experience gives a sense of real communing with reality, but after all experience is not knowledge, but only its source. It must be described and interpreted, and both of these treatments require the presentation of what experience was. The representation of reality, present in the anthropological description and anthropological interpretation, is always preceded and mediated by the experience of reality (Kaniowska 2013: 60).

The situation of the interview, in which the researcher, who collected information for the PEA participated, was designed independently in a specific way. An important role was played by the following factors: quality requirements for the collected material, time pressure, which significantly limited access to a larger group of residents, and finally the inability to record all statements. The pressure caused by these factors meant that the researcher tried to reject the consciousness of personal experience. The representations of personal memory as well as the presentation of the memories of the interlocutors were worked out. The researcher built descriptions of reality that immediately explained it. From several individual statements, the researcher constructed an anonymous statement, reflecting reality regardless of the experience of people who functioned in it. The priority of these activities was to get as many positive answers to questionnaire questions as possible, which would also confirm previously acquired knowledge relating to the subjects studied and would authenticate the assumptions made earlier. So it was 
not about understanding human actions but about explaining the mechanisms and systems of culture. The turnaround which took place in anthropology meant that it was also necessary to re-evaluate these materials. In this place, it is worth referring once again to Kaniowska, who indicates:

Just admitting the thought that cognition is closely related to experience, and the subjects participate in what they meet, completely changes the concepts of cognition and expectations towards the effects of cognition. It is difficult to assume that reality can be described fully and 'from the outside' [...]. The description is still the basic tool available to an anthropologist who wants to understand the reality that is being studied. However, the subject of the description is - what we are now fully aware of in anthropology - the presentation of the real world (Kaniowska 2013: 63; distinction - A.D.).

Another researcher - Kirsten Hastrup emphasises: "Understanding is an imaginative event that connects with human action. Meaning is neither given nor does it derive from a previous system. It happens in practice"(2008: 176). This statement leads to the conclusion that unambiguous and objective knowledge of culture, which was to play a decisive role during ethnographic research, proved impossible during field exploration. This was due to the fact that both experience (thoughts) and the story (expression) about it were not homogeneous wholes. As Bruner noted: "[...] each of them breaks down into smaller processual units, and the interrelations between them often produce their own dynamics" (2011: 18). The situation of the interview is one of many experiences conditioning a specific way of presenting reality through specific performances. This is one of the key phrases in the approach to interpretation of source atlases.

New interpretation possibilities of atlas source materials give the application of the concept of archival memory, that is, the one that strengthens the sentiment to the past and evokes nostalgia. It manifests itself among others through longing for the past time, idealized in comparison with the present times. What follows it is the period of disintegration and decline (compare with Kaźmierska 2007).

Another basic condition changing the research perspective in relation to field records is taking into account the situation of the interview, the way in which the researcher worked and the strategy that was adopted in relation to the narratives that were heard. All interviews conducted during the Atlas studies were only noted in notebooks and questionnaires - pocketbooks. These statements were not recorded. Short answers, but also longer stories, were recorded only in the form of a researcher's note. This situation, despite its technical character, brought farreaching substantive consequences. The ethnographer, who was faced with the enormity and complexity of human experience, from which there was a need to distinguish the facts allowing for the conclusion of culture as a supra-unit and human phenomenon, every time made an extremely difficult decision on subjects 
that were to be kept. ${ }^{7}$ Each of these decisions gave new meanings to messages that were previously marked by the valuation made by their carriers. Representations of the past, which the interlocutors used to construct answers to the questions posed, took the form of a memory representation and as such were noted by the researchers. At the level of meaning, the content included information that the researcher, listening to in the interlocutor's story, considered important. These were messages that, in the opinion of a specialist, did not so much reflect culture as a natural reality, but allowed to build the image of culture as a theoretical being. In this way, human experience was separated from generalized descriptions of cultural phenomena.

Field records regarding the subsequent statements of the villagers were aimed at building such a picture of the studied phenomenon, which would correspond to the theoretical assumptions made before leaving the area. From the field of view of the researcher, the problem of the narrator and his function in the image of reality built in the expression disappeared. The use of such a concept did not allow it to be enough, it even required manipulation of the information heard. As a result, the gathered messages became a conglomerate built from several individual statements. The records made, though built on the basis of many voices, had one author - the researcher. ${ }^{8}$ The inability to accurately record the entire statement forced the ethnographer to note what was considered to be most important. In this way, the descriptions contained in the interview questionnaires make up the representation of the narrative. They constitute an image of reality developed on the basis of representations of the interlocutors' memory, the shape of which was to some extent forced by the specific situation of the interview, as the interlocutors created them in response to the goals presented to them by the researcher and which they themselves attributed to the researcher. An image creating a new quality created during the interaction between the researcher and the villagers, which is the effect of interpersonal contact and experience. The specificity of this type of records was the necessity of moving away from individual conceptualizations of the studied phenomenon, separating the subjective reflection of the narrator and personal experiences accompanying the situation of the interview. This

7 In case of the researcher collecting material for the needs of PEA, two factors had a strong influence on his work: the requirements considering the substantive quality of messages that were noted and the awareness of being controlled by colleagues. To a large extent, it was about separating experiences and individual judgments from facts themselves. And although this naïve and unfeasible pursuit during the field exploration was a priority, it has never been achieved (see Drożdż 2018: $7-47)$.

8 The majority of records referred to in do not have exact information on who provided the specific information. Researchers limited themselves only to making a list of the most important informers (the so-called data sheet) and basic data about them placed at the beginning of the questionnaire. As a rule, this is the only information about the residents of the villages with whom the researchers made direct contact. In the further part of the questionnaire, the source material played a fundamental role. 
type of representation was the basis for building the personal narrative about culture by ethnographers. The conviction about the neutrality of the researcher's records and the objectivity of the images contained in them allowed their use during the preparation of ethnographic maps and the development of commentary texts. The cognitive value of the source materials was based on standardized content. ${ }^{9}$

\section{Conclusions}

Images of reality that reached ethnographers, despite the fact that they were assumed to be relatively homogeneous and predictable (a uniform research questionnaire used in all visited places) was to a large extent different from each other. The so-called 'spontaneous' narratives spoken by the inhabitants of the village constituted a different quality. Although they were also representations of narratives themselves, they did present some fundamental differences. What determined their significance and the role they played in learning about the reality examined was the fact that they constituted an individualized form of narrative. They were not triggered by a question in any way, so they were unique and individual. These features made comparative studies and presentation on ethnographic maps with the help of appropriate signs impossible. Despite this, the message that they contain was so significant that the interlocutor decided to present it in the statement, while the researcher - the listener made the record of it. Reflecting on the narratives heard, the ethnographer used three strategies: drawing spontaneous information into the broader context of the narrative representation referring to the phenomenon studied (without distinguishing it as a separate quality), giving it the function of a separate representation inscribed in the context of a larger statement referring to the question (the researcher's summarizes the narration of the interlocutor and places on the margins of the main statement), giving it the function of a separate representation, which not only fits into the context of the statement but also gives it signs of authenticity (the researcher applies the records in quotes, inserts dialect expressions). At this point, a question arises about the meaning and reason for making such additional records. It can be assumed that it was a way of dealing with a situation where a rigid form of ethnographic research did not adhere to the complexity of the reality being recognized. On the other hand, these representations of spontaneous narratives were the only way of dealing with the existing cognitive dissonance available at that time. Thanks to them, the interpretation of reality contained in the performances gained a wider perspective. Understanding the significance of these performances during the re-

9 The substantive content of questionnaires - notebooks was subject to control. Ethnographers working on the development of the Polish Ethnographic Atlas checked whether the research was carried out reliably. Therefore, the quality of the records made was verified. Gaps and deviations from the assumed results brought about doubts and often led to performing control tests. 
search was almost impossible, it took place at the level of the researcher,s intuition. Only the change of the paradigm allowed to extract a new cognitive value from them. In each of these cases, we deal with various forms of narrative representations that, thanks to the intuition and commitment of the ethnographer, survived after a time to build the story anew. Thus, the changes that took place within the humanities - including anthropology - did not cause the content of the Polish Ethnographic Atlas to be devaluated, but they gave rise to the need for their re-evaluation. Assuming, according to Hastrup: "science is not about explanation, but about imaginative broadening of reality with the metaphorical language of scholars"(2008: 182), using a more current key to anthropological concepts to understand the messages contained in these notations will allow to re-construct new images of the studied reality.

\section{Bibliography}

Bruner E.M.

2011a Przeżycie i jego ekspresje, in: V.W. Turner, E.W. Bruner (eds.), in: Antropologia doświadczenia. Z epilogiem Clifforda Geertza, przeł. E. Klekot, A. Szurek, Kraków, p. 11-40. 2011b Etnografia jako narracja, in: V.W. Turner, E.W. Bruner (eds.), Antropologia doświadczenia. Z epilogiem Clifforda Geertza, przeł. E. Klekot, A. Szurek, Kraków, p. $150-168$.

Drożdż A.

2018 Re/konstrukcje codzienności. Przeszłość w materiałach źródłowych Polskiego Atlasu Etnograficznego, Gdańsk.

Gajek J.

1956 Uwagi do Polskiego Atlasu Etnograficznego. Referat wygłoszony na Sesji Wydziału Nauk Historycznych AN ZSRR 27 IV 1954 r., „Lud”, vol. 42, p. 899-912.

1959 Zadania i metody Polskiego Atlasu Etnograficznego, „Lud” vol. 44, p. 153-204.

1976 Etnograficzne zróżnicowanie obszaru Polski, in: M. Biernacka, B. Kopczyńska-Jaworska, A. Kutrzeba-Pojnarowa, W. Paprocka (eds.), Etnografia Polski. Przemiany kultury ludowej, Wrocław, p. 143-177.

Geertz C.

2005 Opis gesty. W poszukiwaniu interpretatywnej teorii kultury in: C. Geertz, Interpretacja kultur. Wybrane eseje, Kraków, p. 17-48.

Hastrup K.

2008 Droga do antropologii. Między doświadczeniem a teorią, przeł. E. Klekot, Kraków. Huyssen A.

1995 Twilight Memories: Marking Time in a Culture of Amnesia, New York-London. Kaniowska K.

2013 Wokół problematyki przedstawienia ( $z$ punktu widzenia antropologa), „Rocznik Antropologii Historii", vol. III, no. 1 (4), p. 55-68.

Kaźmierska K.

2007 Ramy społeczne pamięci, „Kultura i Społeczeństwo”, vol. 51, no. 2, p. 3-24. 
Kłodnicki Z.

2009 Polska - pogranicze zachodniej i północno-wschodniej prowincji kulturowej w Europie (na podstawie Polskiego Atlasu Etnograficznego), „Ethnologia Europae Centralis”, vol. 9, Brno-Cieszyn-Praha, p. 45-59.

Saryusz-Wolska M. (ed.)

2009 Pamięć zbiorowa i kulturowa. Współczesna perspektywa niemiecka, Kraków. 